\title{
LA PRESTACIÓN DEL CONSENTIMIENTO INFORMADO EN MATERIA DE SALUD EN EL NUEVO SISTEMA DE APOYOS AL EJERCICIO DE LA CAPACIDAD'
}

The provision of health-informed consent in the new capacity support system

\author{
M. ${ }^{a}$ DEL CARMEN GONZÁLEZ CARRASCO \\ Universidad de Castilla-La Mancha \\ maria.gonzalez@uclm.es
}

Cómo citar/Citation

González Carrasco, M. ${ }^{a}$ del C. (2021).

La prestación del consentimiento informado en materia de salud en el nuevo sistema de apoyos al ejercicio de la capacidad Derecho Privado y Constitución, 39, 213-247. doi:https://doi.org/10.18042/cepc/dpc.39.01

(Recepción: 08/09/2021 ; aceptación tras revisión: 07/10/2021; publicación: 10/12/2021)

\section{Resumen}

La dignidad de la persona con discapacidad y el derecho al libre desarrollo de la personalidad en condiciones de igualdad inspiran el sistema de apoyos diseñado por la nueva Ley 8/2021, de 2 de junio, por la que se reforma la legislación civil y procesal para el apoyo a las personas con discapacidad en el ejercicio de su capacidad jurídica. La nueva ley modifica el título XI CC extendiendo sus efectos a otras normas. Sin embargo, su necesario ajuste con las decisiones a adoptar en relación con el tratamiento sanitario de la persona con discapacidad ha quedado, al igual que ha

1 Trabajo realizado en el marco del Proyecto de Investigación PGC2018-098683-B-I00, del Ministerio de Ciencia, Innovación y Universidades (MCIU) y la Agencia Estatal de Investigación (AEI) cofinanciado por el Fondo Europeo de Desarrollo Regional (FEDER) titulado «Protección de consumidores y riesgo de exclusión social». 
ocurrido con el resto de otras situaciones reguladas en leyes especiales, al margen de las previsiones del legislador. Este trabajo aborda el análisis de las modificaciones que el nuevo paradigma de apoyos a la capacidad requiere introducir en la regulación del consentimiento informado contemplado en la Ley 41/2002, de 14 de noviembre, básica reguladora de la autonomía del paciente y de los derechos y obligaciones en materia de información y documentación clínica, así como en otras normas reguladoras de actuaciones sanitarias más específicas.

\title{
Palabras clave
}

Discapacidad; capacidad jurídica; medidas de apoyo; autonomía del paciente; consentimiento informado; representación.

\begin{abstract}
The dignity of the person with disabilities and the right to the free development of the personality in conditions of equality inspire the support system designed by the new Law 8/2021, of June 2, which reforms the civil and procedural legislation for the support of people with disabilities in the exercise of their legal capacity. The new law modifies Title XI CC by extending its effects to other regulations. However, its necessary adjustment with the decisions to be taken in relation to the health treatment of persons with disabilities has remained, as has happened with the rest of other situations regulated in special laws, outside the provisions of the legislator. This paper addresses the analysis of the modifications that the new paradigm of capacity support requires to be introduced in the regulation of informed consent contemplated in Law 41/2002, of November 14, basic regulation of patient autonomy and rights and obligations in terms of information and clinical documentation, as well as in other regulatory standards of more specific health actions.
\end{abstract}

\section{Keywords}

Disability; legal capacity; support measures; patient autonomy; informed consent; representation. 


\section{SUMARIO}

I. INTRODUCCIÓN. II. LA CAPACIDAD DE OBRAR DE LAS PERSONAS CON DISCAPACIDAD CON ANTERIORIDAD A LA LEY 8/2021. III. LOS APOYOS A LA CAPACIDAD EN EL ÁMBITO SANITARIO: 1. Las modificaciones operadas por la Ley $26 / 2011$, de adaptación normativa a la Convención internacional sobre los derechos de las personas con discapacidad, en la normativa de autonomía del paciente. 2. ¿̇Por qué es preciso modificar la normativa reguladora de la autonomía del paciente? IV. INFORMACIÓN Y CONSENTIMIENTO ESTÁN EN DISTINTOS PLANOS DE AUTONOMÍA PERSONAL. V. EL APOYO A LA PRESTACIÓN DEL CONSENTIMIENTO INFORMADO Y SUS LÍMITES EN MATERIA DE SALUD: 1. EI consentimiento "por representación» en caso de ausencia de medidas formales de apoyo. 2. El consentimiento informado en caso de existencia de medidas de apoyo formal. 3. Beneficencia versus autonomía: el mejor interés de la persona necesitada de apoyo como límite a las decisiones en materia de salud. VI. LOS APOYOS A LA PRESTACIÓN DEL CONSENTIMIENTO INFORMADO EN CASOS ESPECIALES: 1. Ensayos clínicos. 2. Interrupción voluntaria del embarazo. 3. Trasplantes. 4. Reproducción asistida. 5. Eutanasia. VII. BREVE RESUMEN DE PROPUESTAS. BibLIOGRAFía.

\section{INTRODUCCIÓN}

El art. 49 CE contempla como principio rector de la política económica y social la realización de una política de previsión, tratamiento, rehabilitación e integración de las personas con discapacidad, a quienes los poderes públicos deben prestar la atención especializada que requieran y amparar especialmente para el disfrute de los derechos que su título I otorga a todos los ciudadanos. Este elenco de derechos se encabeza, a su vez, con el art. $10 \mathrm{CE}$, según el cual, «la dignidad de la persona, los derechos inviolables que le son inherentes, y el libre desarrollo de la personalidad [...] se interpretarán de conformidad con la Declaración Universal de Derechos Humanos y los tratados y acuerdos internacionales sobre las mismas materias ratificados por España».

La Convención de Nueva York, firmada el 13 de diciembre de 2006, e incorporada a nuestro ordenamiento jurídico por instrumento de ratificación de 23 de noviembre de 2007, proclama en su art. 12.2 que las personas 
con discapacidad tienen capacidad jurídica en igualdad de condiciones con las demás en todos los aspectos de la vida, y obliga a los Estados partes a adoptar las medidas pertinentes para proporcionar a las personas con discapacidad acceso al apoyo que puedan necesitar en el ejercicio de su capacidad jurídica, con pleno respeto a su dignidad humana y procurando su derecho a la adopción de sus propias decisiones.

La dignidad del paciente es también el principio básico que rige la relación médico asistencial. Según el apdo. primero del art. 2 de la Ley 41/2002, de 14 de noviembre, básica reguladora de la autonomía del paciente y de derechos y obligaciones en materia de información y documentación clínica (en adelante, LAP), «la dignidad de la persona humana, el respeto a la autonomía de su voluntad y a su intimidad orientarán toda la actividad encaminada a obtener, utilizar, archivar, custodiar y transmitir la información y la documentación clínica», y según la misma ley, toda actuación en el ámbito sanitario requiere el consentimiento del paciente, después de haber recibido una información adecuada, que le permita decidir entre las opciones disponibles; esto es, exige el consentimiento informado del paciente, que es definido por el art. 3 como "la conformidad libre, voluntaria y consciente de un paciente, manifestada en el pleno uso de sus facultades después de recibir la información adecuada, para que tenga lugar una actuación que afecte a su salud $»^{2}$.

Lo anteriormente dicho es así con independencia de la conservación por parte del paciente de sus facultades intelectivas y sensoriales. El art. 25 de la Convención de Nueva York, en su apdo. d), establece que los Estados exigirán a los profesionales de la salud que presten a las personas con discapacidad una atención de la misma calidad que a las demás personas sobre la base de un consentimiento libre e informado, entre otras formas mediante la sensibilización respecto de los derechos humanos, la dignidad, la autonomía y las necesidades de las personas con discapacidad a través de la capacitación y la promulgación de normas éticas para la atención de la salud en los ámbitos público y privado; y el apdo. 7 del art. 9 de la Ley 41/2002, dirigido a regular el consentimiento informado por representación, ordena la adecuación de «la prestación del consentimiento por representación a las circunstancias, de forma proporcionada a las necesidades que haya que atender, siempre en favor del paciente y con respeto a su dignidad personal», haciendo partícipe

2 Así lo reconoce también expresamente el art. 5 del Convenio del Consejo de Europa para la protección de los derechos humanos y la dignidad del ser humano con respecto a las aplicaciones de la biología y la medicina, suscrito en Oviedo el 4 de abril de 1997, que entró en vigor en España el día 1 de enero de 2000 (en adelante, Convenio de Oviedo); y el art. 3.2 de la Carta Europea de Derechos Humanos 2000/C 364/01. 
al paciente en la medida de lo posible en la toma de decisiones a lo largo del proceso sanitario. Para conseguir este resultado en relación con las personas con discapacidad, y en virtud de la modificación operada por la Ley 26/2011, de 1 de agosto, de Adaptación Normativa a la Convención Internacional sobre los Derechos de las Personas con Discapacidad, el art. 9 de la LAP acaba ordenando las medidas de apoyo pertinentes, incluida la información en formatos adecuados, para favorecer que las personas con discapacidad puedan prestar por sí solas su consentimiento.

El objetivo del presente estudio es determinar si la normativa que actualmente regula la prestación del consentimiento informado en materia de salud resulta ya conforme con los principios del Convenio de Nueva York o si, por el contrario, necesita de una modificación para ser adecuada a dicha norma y al nuevo paradigma de la capacidad de surgido de la entrada en vigor de la Ley $8 / 2021$, de 2 de junio, reguladora de los apoyos a las personas con discapacidad en el ejercicio de su capacidad de obrar (en adelante, Ley 8/2021). La cuestión expuesta adquiere carácter constitucional, no solo de forma indirecta, como parte integrante de la correcta prestación por parte de los profesionales y de los servicios sanitarios públicos y privados de cara a la consecución del derecho a la salud (cfr. art. 6 LAP y art. 5 de la Ley 44/2003, de 21 de noviembre, de Ordenación de las Profesiones Sanitarias), sino también en su vertiente de «derecho fundamental derivado» ${ }^{3}$ (Cadenas Osuna, 2018: 2010).

\section{LA CAPACIDAD DE OBRAR DE LAS PERSONAS CON DISCAPACIDAD CON ANTERIORIDAD A LA LEY 8/2021}

A pesar de la incorporación del art. 12.2 de la Convención de Nueva York al ordenamiento jurídico interno español desde su ratificación por España el 23 de noviembre de 2007, con la consiguiente obligación por parte del Estado de reconocer que «las personas con discapacidad tienen capacidad jurídica en igualdad de condiciones con las demás en todos los aspectos de la vida», la protección de la persona con discapacidad imperante en el nuestro Código Civil hasta el 3 de septiembre de 2021 (fecha de entrada en vigor de la Ley 8/2021) pivotaba sobre la distinción entre capacidad jurídica y capacidad de obrar, y sobre la limitación judicial de la capacidad de obrar de la persona con

3 SSTS (1a) 12 de enero de 2001 (RJ 2001/3) y 11 de mayo de 2001 (RJ 2001/6197)]. La STC 37/2011, de 28 de marzo, considera que el derecho a recibir una información previa a un consentimiento informado es garantía del derecho fundamental a la integridad física y moral. 
discapacidad a través de su incapacitación o de la modificación judicial de su capacidad. Es cierto que, tras una primera etapa en la que la incapacitación era absoluta, la Ley 13/1983, de 24 de octubre, de Reforma del Código Civil en materia de tutela, modificó el Código Civil estableciendo la necesidad de que la resolución judicial determinase los actos para los que la persona era considerada incapaz de obrar o tenía restringida su capacidad.

En ese contexto, la Ley 15/2015, de 2 de julio, de la Jurisdicción voluntaria (en adelante, LJV) supuso un primer acercamiento real a los principios de la Convención de Nueva York, puesto que modificó los procedimientos de incapacitación judicial, que pasaron a denominarse procesos de «modificación judicial de la capacidad».

Junto con las situaciones de incapacitación o capacidad judicialmente modificada, se contemplaba la figura del incapaz natural, cuyos actos se regulaban en algunas normas concretas del Código Civil y cuya situación estaba llamada a ser solucionada mediante una declaración judicial de incapacitación o modificación judicial de la capacidad a través de la cual, se nombrase tutor $-\mathrm{O}$ curador - para la persona necesitada de dichas medidas, o bien se formalizase en una de estas dos figuras la previa existencia del guardador de hecho.

Los rasgos anteriormente descritos habían subsistido como principios reguladores de la capacidad de obrar, a pesar de la incorporación de la Convención de Nueva York a nuestro ordenamiento jurídico interno por instrumento de ratificación de noviembre de 2007.

Cierto es que, a partir de la STS (1a) de 29 abril de 2009 (RJ 2009, 2901), interpretativa del impacto en nuestro sistema jurídico de la Convención de Nueva York, diversos pronunciamientos judiciales vinieron a demostrar que «los criterios aplicados tras la Ley 13/1983 estaban siendo revisados en favor de un criterio de flexibilidad tendente a la constitución de curatelas con funciones de mera asistencia, y al diseño de construcciones que no correspondían ni con la curatela ni con la tutela, tal y como las mismas estaban configuradas en el Código civil»(De Salas Murillo, 2013: 11-48). Así, en la última década, el Tribunal Supremo había comenzado a aplicar expresamente los principios de la Convención de Nueva York, propugnando una interpretación de nuestro ordenamiento jurídico civil conforme a la misma, y accediendo a la constitución de curatelas de asistencia en supuestos de trastornos psíquicos y deterioros cognitivos en los que en la instancia se había nombrado tutor a la persona con capacidad judicialmente modificada. Ejemplo de ello es la STS (1a) de 27 de noviembre de 2014 (RJ 2014, 6032).

También es cierto que, paralelamente, nuestro ordenamiento interno ya había comenzado a desarrollar algunos aspectos sectoriales dela Convención de Nueva York a través de la Ley 26/2011, de Adaptación Normativa a la Convención Internacional sobre los Derechos de las Personas con Discapacidad. 
El objetivo de esta ley, refundida por RDLeg 1/2013, de 29 de noviembre, por el que se aprobó el texto refundido de la Ley General de Derechos de las Personas con Discapacidad y de su Inclusión Social (en adelante, TR RDLeg 1/2013), fue adaptar un gran número de normas vigentes en nuestro ordenamiento para lograr el principio de accesibilidad universal de las personas con discapacidad y diseño para todos en el acceso a la contratación pública y privada y en el acceso de bienes, servicios, en el acceso al empleo, en el régimen de propiedad urbana, en la enseñanza y en la sanidad. Además, con posterioridad, otras normas habían ido avanzando en el objetivo de avanzar en el reconocimiento de la plena capacidad a las personas con discapacidad física, psíquica y sensorial ${ }^{4}$. Sin embargo, a pesar de las sucesivas reformas apuntadas, el régimen de la capacidad de obrar de las personas con discapacidad intelectual previsto en el Código Civil no se había adecuado al sistema diseñado en la Convención de Nueva York hasta la entrada en vigor, el 3 de septiembre de 2021, de la Ley 8/2021.

En virtud de la nueva norma desaparece del nuevo título XI del Código Civil toda referencia al incapaz natural y la tutela, como régimen de representación legal, quede relegada al ámbito de la minoría de edad, asumiendo la curatela el papel protagonista dentro de las medidas de apoyo formal de la persona con discapacidad, como figura más idónea para su protección, tal y como también había adelantado la Fiscalía General del Estado en su Instrucción 3/2010 «Sobre la necesaria fundamentación individualizada de las medidas de protección o apoyo en los procedimientos sobre determinación de la capacidad de las personas».

Por otra parte, el nuevo art. $255 \mathrm{CC}$, in fine, parte del carácter subsidiario de los apoyos representativos, de la institucionalización de la guarda de hecho como apoyo suficiente y permanente a la capacidad de obrar de la persona y de la preferencia por las medidas de apoyo voluntarias, no solo de aquellas que la persona constituya en previsión de una futura necesidad

4 Así, la reforma del Código Penal llevada a cabo por la Ley Orgánica 1/2015, de 30 de marzo, la nueva legislación de jurisdicción voluntaria (Ley 15/2015, de 2 de julio, modificada por la Ley 4/2017, de 24 de junio, precisamente en relación con el derecho de las personas con discapacidad a contraer matrimonio en igualdad de condiciones), la Ley Orgánica 1/2017, de 13 de diciembre, para garantizar la participación de las personas con discapacidad sin exclusiones, la Ley Orgánica 2/2018, de 5 de diciembre, para la modificación de la Ley del Régimen Electoral General, para garantizar el derecho de sufragio de todas las personas con discapacidad, y la Ley Orgánica 2/2020, de 16 de diciembre, de modificación del Código Penal para la erradicación de la esterilización forzada o no consentida de personas con discapacidad incapacitadas judicialmente.

5 Disponible en: https://bit.ly/3jlALYz. 
de apoyo a su capacidad (autocuratela y poderes preventivos), sino en virtud de la propia apreciación actual de la concurrencia de circunstancias que puedan dificultarle el ejercicio de su capacidad jurídica en igualdad de condiciones con las demás (art. 255 I CC); en ambos casos, con el alcance que se exprese en el acuerdo de apoyos otorgado en escritura pública.

Esta nueva regulación invita a una reflexión sobre el funcionamiento del nuevo sistema de apoyos en el ámbito de la salud, que exige modificaciones más profundas que las operadas en la LAP por la Ley 26/2011, de adaptación normativa a la Convención Internacional sobre los Derechos de las Personas con Discapacidad, en la normativa de autonomía del paciente.

\section{LOS APOYOS A LA CAPACIDAD EN EL ÁMBITO SANITARIO}

\section{LAS MODIFICACIONES OPERADAS POR LA LEY 26/2011, DE ADAPTACIÓN NORMATIVA A LA CONVENCIÓN INTERNACIONAL SOBRE LOS DERECHOS DE LAS PERSONAS CON DISCAPACIDAD, EN LA NORMATIVA DE AUTONOMÍA DEL PACIENTE}

En el ámbito sanitario, las modificaciones operadas por la Ley 26/2011 afectaron al art. 4 de la LAP, por la que se añadió un último inciso al apdo. 5 del art. 9, según el cual, «[...] Si el paciente es una persona con discapacidad, se le ofrecerán las medidas de apoyo pertinentes, incluida la información en formatos adecuados, siguiendo las reglas marcadas por el principio del diseño para todos de manera que resulten accesibles y comprensibles a las personas con discapacidad, para favorecer que pueda prestar por sí su consentimiento».

Iguales criterios de formatos adecuados y diseño para todos en la información y el consentimiento a prestar por donantes y receptores de técnicas de reproducción asistida humana son los que inspiraron las dos modificaciones operadas en la Ley 14/2006, de 26 de mayo, de Técnicas de Reproducción Humana Asistida (en adelante, LTRHA), y la afectante al art. 4.1 y al art. $6^{6}$ de la Ley 30/1979, de 27 de octubre, sobre extracción y trasplante de órganos.

6 En esta norma, la Ley 26/2011 incorporó un último párrafo plenamente acorde con el espíritu del Convenio de Nueva York que, adelantándose a la Ley 8/2021, dispone que «en el caso de que el receptor sea una persona con discapacidad, deberán tenerse en cuenta las circunstancias personales del individuo, su capacidad para tomar dicha decisión en concreto y contemplarse la prestación de apoyo para la toma de estas decisiones. Tratándose de personas con discapacidad con necesidades de apoyo para 
También fue modificada por dicha norma la Ley 14/1986, de 25 de abril, General de Sanidad, para incorporar en su art. 10 la necesidad de diseño para todos en la oferta de servicios de salud, así como, en el ámbito programático, su art. 18, para ordenar la promoción de los métodos de detección precoz.

Otras normas sanitarias modificadas por la Ley 26/2011 se dirigieron a evitar las situaciones de discriminación por razón de discapacidad en relación con el acceso a los servicios de salud (apdo. 2 del art. 3 de la Ley 16/2003, de 28 de mayo, de cohesión y calidad del Sistema Nacional de Salud) y con el acceso y el proceso formación de los profesionales sanitarios con discapacidad (apdo. 3 del art. 22 de la Ley 44/2003, de 21 de noviembre, de ordenación de las profesiones sanitarias).

Sin embargo, la Ley 8/2021 no ha modificado la $\mathrm{LAP}^{7}$. Su art. 9 sigue haciendo referencia a un paciente que «no es capaz», y refiriéndose a las situaciones de incapacitación, así como a la representación legal «del incapaz» en contraste con la preferencia del nuevo sistema de apoyos por los no representativos. Únicamente, ya en fase de tramitación de la Ley 8/2021 ante el Senado, se introdujo una mención al consentimiento informado y a los internamientos forzosos, al único efecto de excluir estos dos supuestos y en general, los sometidos a una normativa propia, del régimen general de autorización judicial previa necesaria para la representación del discapacitado en el ámbito de sus derechos de carácter personal y familiar, limitándose el nuevo art. 287 CC a someterlos a su regulación especial. La norma se limita a aclarar que la normativa reguladora del consentimiento informado es una legislación especial sujeta a reglas propias, sin resolver el problema de la inseguridad jurídica de los profesionales sanitarios ante los profundos cambios exigidos por el nuevo paradigma de apoyos a la capacidad de las personas con discapacidad.

la toma de decisiones, se estará a la libre determinación de la persona una vez haya dispuesto de los apoyos y asistencias adecuados a sus concretas circunstancias».

7 No se trata simplemente de una cuestión de tiempo, pues sí ha sido incorporado al art. 15.2 LAP un nuevo apdo. 5 por la disposición final 13 de la Ley Orgánica $8 / 2021$, de 4 de junio, de protección integral a la infancia y la adolescencia frente a la violencia, que se tramitó de forma paralela a la Ley 8/2021. El legislador ya había ordenado la modificación de la LAP en la disp. final tercera de la LO /2020, de 16 de diciembre, de modificación del Código Penal para la erradicación de la esterilización forzada o no consentida de personas con discapacidad incapacitadas judicialmente. La futura modificación debería incorporar las exigencias del nuevo sistema de apoyos a la capacidad de las personas con discapacidad. 


\section{2. ¿̇POR QUÉ ES PRECISO MODIFICAR LA NORMATIVA REGULADORA DE LA AUTONOMÍA DEL PACIENTE?}

La capacidad para prestar el consentimiento informado en los casos de minoría de edad o de discapacidad intelectual en sentido amplio se halla regulada en el art. 9 de la LAP, en relación con los arts. 4, 5 y 8 del mismo texto legal.

En la fecha en la que la LAP fue aprobada, y a pesar de la clara mejora que la misma supuso en comparación con la incipiente regulación del consentimiento en la Ley 10/1986, General de Sanidad, la doctrina más autorizada ya había advertido del confuso panorama legislativo que dicha norma contribuiría a dibujar, augurando que la norma no iba a ser capaz de «resolver todos los problemas que pueden plantearse en un ámbito en el que los profesionales necesitan criterios seguros para tomar decisiones sin incurrir en responsabilidad», habida cuenta de su "desconocimiento del funcionamiento de las instituciones de guarda y protección de menores e incapaces, así como de los controles previstos para su ejercicio» (Parra Lucán, 2003: 1902).

Al igual que ocurrió en el momento de su aprobación, tras la entrada en vigor de la Ley 8/2021, la LAP vuelve a ser funcionar con independencia del nuevo sistema de apoyos a la capacidad. Pero si entonces se achacó a la norma el no haberse ajustado al sistema de funcionamiento y control de las instituciones de protección de las personas con capacidad modificada, en la actualidad cabe pensar que el reproche ha de ser de signo contrario. Esto es: ni la mejor intencionada de las interpretaciones puede ocultar que, tanto la normativa estatal como la autonómica ${ }^{8}$ dictada en el ámbito del consentimiento informado en el campo de la salud, requieren, desde luego, una modificación formal que elimine de su texto las actuales referencias a la incapacidad y a la modificación judicial de la capacidad. La cuestión es

8 Es bien sabido que en nuestro ordenamiento jurídico, tanto las CC. AA. con derecho civil foral propio en materia de persona y capacidad en virtud de lo dispuesto en el art. 149.1.8 $\mathrm{CE}$ como aquellas otras sujetas al derecho civil común han dictado normas sobre autonomía del paciente. No es este el lugar de analizar la cuestión competencial en el ámbito del consentimiento informado en el ámbito de la salud. Sin embargo, creo que es correcto entender, con Parra Lucán (2013: 1904) que, tanto aquellas CC. AA. que no tienen un derecho civil propio en materia de capacidad y que, sin embargo, regulan aspectos relacionados con el consentimiento por representación, como aquellas otras que sí tienen un derecho civil propio en relación con esta cuestión, regulan el consentimiento informado en virtud de su competencia de ordenación de la sanidad, esto es, como derechos de los pacientes y deberes de los profesionales en virtud de su competencia en materia de sanidad, y no como normas sobre capacidad. 
si dichas normas exigen, además, una adaptación de fondo a los principios del nuevo sistema. En definitiva, cabe preguntarse si nos encontramos ante la necesidad de una reforma legal postergada, o ante la constatación de que los apoyos representativos en la prestación del consentimiento informado en materia de salud serán la regla general frente a la excepcionalidad con que se contemplan en la Ley 8/2021, independientemente del nombre con el que finalmente el legislador acuerde identificar dicha medida de protección de la persona ${ }^{9}$. La respuesta fácil es la segunda, pero no parece ser la adecuada a la intención del legislador. Según la exposición de motivos de la Ley 8/2021, «no se trata, pues, de un mero cambio de terminología que relegue los términos tradicionales de "incapacidad" e "incapacitación" por otros más precisos y respetuosos, sino de un nuevo y más acertado enfoque de la realidad, que advierta algo que ha pasado durante mucho tiempo desapercibido: que las personas con discapacidad son titulares del derecho a la toma de sus propias decisiones». En definitiva, el espíritu de la ley no es cambiarlo todo para que nada cambie. El nuevo paradigma que impone la norma implica un esfuerzo de adecuación formal y material de la LAP a las previsiones de la Ley 8/2021.

La concreción de los cambios precisos requiere un análisis del proceso de toma de decisiones previsto en la Ley 41/2002 que aborde de forma diferenciada la fase de información de la fase de decisión y expresión del consentimiento previamente informado. Esto es, la capacidad del paciente para obtener la información asistencial, de un lado, de la capacidad para otorgar un consentimiento válido para el tratamiento o la intervención en el ámbito de su salud, de otro. Y, en segundo lugar, requiere analizar el binomio autonomía-beneficencia para dar respuesta a la cuestión de la existencia en el ámbito sanitario de límites específicos que puedan matizar la primacía de la voluntad, deseos y preferencias expresados por la persona discapacitada en el ámbito de su salud.

\section{INFORMACIÓN Y CONSENTIMIENTO ESTÁN EN DISTINTOS PLANOS DE AUTONOMÍA PERSONAL}

Según lo dispuesto en el art. 5 LAP, el paciente es siempre y en todo caso, el titular del derecho a la información asistencial (apdo. primero), y como tal

9 STS (1a) de 29 abril 2009 (RJ 2009, 2901), cuando afirmaba que «una medida de protección como la incapacitación, independientemente del nombre con el que finalmente el legislador acuerde identificarla, solamente tiene justificación con relación a la protección de la persona». 
«será informado, incluso en caso de incapacidad, de modo adecuado a sus posibilidades de comprensión, cumpliendo con el deber de informar también a su representante legal» (apdo. segundo). Cuando el paciente, según el criterio del médico que le asiste, «carezca de capacidad para entender la información a causa de su estado físico o psíquico, la información se pondrá en conocimiento de las personas vinculadas a él por razones familiares o de hecho». Todo ello, sin perjuicio de informar al paciente de forma adecuada a sus posibilidades de comprensión, pues aun en los anteriores casos (que requieren un consentimiento por representación, según el art. 9.3), «el paciente participará en la medida de lo posible en la toma de decisiones a lo largo del proceso sanitario» (art. 9.5). Detengámonos en el escenario que plantea el apartado transcrito.

La norma parte de un sistema de incapacitación (rectius, modificación judicial de la capacidad) que, antes de la Ley 8/2021, se acompañaba de la tutela (a veces, curatela de salud) del «incapaz», pero en el que las situaciones de apoyo fáctico o sustitución en virtud de una guarda de hecho en la toma de decisiones eran, sin embargo, las más frecuentes. Ello es fácilmente entendible habida cuenta de que el envejecimiento de la sociedad ha llevado consigo un aumento del número de pacientes con deterioro cognitivo que reciben asistencia sanitaria con el apoyo fáctico de sus familiares cercanos o de los responsables de los centros donde residen en régimen de internamiento «voluntario» ${ }^{10}$. Sin embargo, y sin perjuicio del régimen de previsto en sus seis

10 La LEC regula el internamiento involuntario por razón de trastorno psíquico en su artí. 763. La LO 8/2015, de 22 de julio, ha dotado de carácter de ley orgánica a dicho artículo, en cumplimiento de la STC 132/2010, de 2 de diciembre, y la propia Ley $8 / 2021$ se remite a la normativa específica en la materia a la hora de regular los actos para los que el apoyo representativo necesita autorización judicial.

El internamiento involuntario se condiciona en la LEC a la concurrencia de un trastorno psíquico en la persona y a que el trastorno sea de tal intensidad que no le permita a la persona ser consciente de la necesidad de ser internada (art. 763 LEC). Con independencia de la necesidad de adecuar dicho artículo al derecho a la protección de la libertad personal establecido en el art. 14 de la Convención de Nueva York (Informe 2019 del Comité de la ONU sobre los derechos de las personas con discapacidad: https://www.plenainclusion.org/sites/default/files/informe_de_ naciones_unidas_sobre_los_derechos_de_las_personas_con_discapacidad.pdf), los internamientos de personas de la tercera edad no están per se comprendidos en dicha norma si la persona mayor de edad no sufre un trastorno psíquico intenso que le impida decidir por sí misma. Por lo tanto, es necesario el consentimiento del adulto mayor o de su representante legal con autorización judicial, pues el nuevo art. 287 CC solo excluye el consentimiento informado por representación y el internamiento sometido a una regulación específica (que es el forzoso por trastorno psíquico). 
disposiciones transitorias, tras la entrada en vigor de la Ley 8/2021 ya no se puede seguir hablando de incapacidad de obrar en ninguna de las situaciones o grados de discapacidad física, de discapacidad intelectual o de deterioro cognitivo. De acuerdo con el régimen actualmente vigente, la redacción de los apdos. 2 y 3 del art. 5 LAP debería expresarse de la siguiente manera:

1. El paciente será informado, incluso en el caso de que, a juicio del médico responsable, requiera de apoyos para el ejercicio de su capacidad, de modo adecuado a sus posibilidades de comprensión, cumpliendo con el deber de informar también a la persona que, de hecho, o en virtud de acuerdo o curatela, representativa o no, lo acompañe ejerciendo el apoyo necesario.

2. Cuando el paciente, según el criterio del médico que le asiste, no se encuentre en condiciones de entender la información a causa de su estado físico o psíquico, la información se pondrá en conocimiento de las personas vinculadas a él por razones familiares o de hecho.

Es evidente que al profesional responsable del tratamiento no le es exigible conocer la existencia de una curatela representativa (excepcional y dirigida a actos concretos, ex art. 269 II CC), pero tampoco la existencia de una curatela ordinaria (preferente a aquella, ex art. 269 III CC), tanto más cuando en el sistema previsto por la Ley 8/2021, el juez no proveerá al sujeto necesitado de apoyos de un apoyo institucional si comprueba la suficiencia de la guarda de hecho que hasta entonces había venido recibiendo (art. 269 CC).

Por otro lado, avanzando en el modo de transmitir la información asistencial actualmente diseñado en el art. 5 LAP, ha de analizarse también la incidencia del nuevo paradigma en aquellos supuestos excepcionales en los que el paciente no va a recibir la información previa a la intervención sanitaria, y que plantean interés en orden a su concurrencia en casos en los que el paciente es una persona con necesidad de apoyos en el ejercicio de su capacidad.

El primero de ellos viene constituido por la concurrencia de una urgencia vital, esto es, la que conlleva un riesgo inmediato grave para la integridad física o psíquica del enfermo, siendo imposible conseguir su autorización. Aunque el art. 9 LAP contempla este supuesto en sede de consentimiento informado, con el efecto de eximir a los profesionales obligados del deber de recabarlo para la intervención, es aplicable, a fortiori, al deber de informar al paciente, y por ello, el art. 9.2 exige informar a los familiares o personas vinculadas de hecho con él cuando las circunstancias lo permitan. En este punto no existe necesidad de modificación alguna, pues el principio de autonomía cede ante el de beneficencia en estos casos, sin que, por otra parte, las personas vinculadas por razones familiares o de hecho que deben ser informadas si las 
circunstancias lo permiten deban acreditar su condición de persona de apoyo. Además, desde la entrada en vigor de la Ley 8/2021, el Código Civil muestra su preferencia por la persona que de hecho viene prestando el apoyo necesario a la persona con discapacidad, al considerar subsidiarias el resto de las medidas de apoyo (art. 269 III CC).

El segundo caso en el que el profesional sanitario responsable de la asistencia puede obviar la información debida al paciente viene constituido por el llamado "privilegio terapéutico» (o necesidad terapéutica), que concurre en los supuestos en los que, por razones objetivas, el conocimiento de su propia situación pueda perjudicar su salud de manera grave. Llegado este caso, el médico debe dejar constancia razonada de las circunstancias que le han llevado a la adoptar la decisión de no informar al paciente en la historia clínica y comunicará su decisión a las personas vinculadas al paciente por razones familiares o de hecho. El supuesto no se dirige especialmente a los supuestos de discapacidad intelectual o deterioro cognitivo previos, pues será precisamente en estos casos en cuando la información recibida se habrá adecuado ya a las posibilidades de comprensión de la persona con discapacidad. Además, quizá sea en estos casos en los que, precisamente por esta adecuación previa, la información tendrá un potencial menor de afectación de cara a la recuperación de la salud del paciente. Aquí reside principalmente el principal riesgo de vuelta al paternalismo médico a través de esta medida - que debe excepcional— debido a una inadecuada utilización consistente en considerarlo aplicable a categorías de pacientes (a aquellos con alteraciones psíquicas o deterioro cognitivo), o para evitar rechazos al tratamiento en lugar de ser aplicado a situaciones concretas de riesgo de daño psicológico severo (Galán Cortés, 2001: 194).

Tampoco será informado el paciente cuando haya renunciado expresamente a recibir la información, conforme a lo dispuesto en el art. 9.1 LAP. Dicha renuncia está limitada por el interés de la salud del propio paciente, de terceros, de la colectividad y por las exigencias terapéuticas del caso y no exime del deber de recabar su consentimiento previo para la intervención. En el sistema de capacidad de obrar anterior a la Ley 8/2021, cuando un paciente carecía de capacidad suficiente para comprender el alcance de la información, debía ser informado su representante legal o, careciendo del mismo (bien por incapacidad transitoria derivada de la propia patología, bien por tratarse de un incapaz natural), las personas vinculadas a él por razones de hecho (en la práctica, no solo guardadores de hecho, también familiares con independencia del grado de parentesco, o simples acompañantes en el ingreso hospitalario). Si el paciente no tenía capacidad para ser plenamente informado, tampoco la tenía para rechazarla, por lo que no podía oponerse eficazmente a que la información se trasladase a dichas personas. En la actualidad, según la nueva redacción del art. 269.2 CC, el paciente necesitado de apoyo en su capacidad 
es un sujeto «cuya voluntad, deseos y preferencias han de ser respetados», por lo que «sólo en casos excepcionales, cuando, pese a haberse hecho un esfuerzo considerable, no sea posible determinar la voluntad, deseos y preferencias de la persona, las medidas de apoyo podrán incluir funciones representativas. En este caso, en el ejercicio de esas funciones se deberá tener en cuenta la trayectoria vital de la persona con discapacidad, sus creencias y valores, así como los factores que ella hubiera tomado en consideración, con el fin de tomar la decisión que habría adoptado la persona en caso de no requerir representación». Este nuevo paradigma colocaría al profesional sanitario en una situación de incertidumbre ante la eventualidad de que la persona que necesitada de apoyos en el ejercicio de su capacidad exprese firmemente su deseo de que sus familiares o curadores representativos tampoco sean informados. Afortunadamente, la práctica discurre de otra forma, y la cláusula general de salvaguarda de la salud del paciente que recoge en el art. 9.1 LAP permite al profesional responsable del tratamiento obviar el rechazo al suministro de información expresado por aquel, e informar a las personas que, de hecho, o a través de alguna de las fórmulas voluntarias o judiciales previstas por la Ley 8/2021, ejercen o están llamadas a ejercer las funciones de apoyo del paciente.

\section{EL APOYO A LA PRESTACIÓN DEL CONSENTIMIENTO INFORMADO Y SUS LÍMITES EN MATERIA DE SALUD}

\section{EL CONSENTIMIENTO «POR REPRESENTACIÓN»EN CASO DE AUSENCIA DE MEDIDAS FORMALES DE APOYO}

En cuanto al consentimiento informado a otorgar por personas mayores de edad, de acuerdo con el art. 9.3.c) de la LAP, se otorgará el consentimiento por representación en los siguientes supuestos:

En primer lugar, cuando el paciente «no sea capaz de tomar decisiones», a criterio del médico responsable de la asistencia, o su estado físico o psíquico no le permita hacerse cargo de su situación. En este supuesto caben tanto las situaciones de imposibilidad transitoria de adoptar decisiones debido a la propia patología presentada por el paciente como las situaciones de discapacidad intelectual o deterioro cognitivo determinantes de lo que hasta la fecha se ha venido considerando «incapacidad natural». A este último supuesto se refiere la norma cuando afirma que «si el paciente carece de representante legal, el consentimiento lo prestarán las personas vinculadas a él por razones familiares o de hecho».

La norma ya era distorsionante en el sistema anterior a la Ley 8/2021. El consentimiento para un acto médico no puede ser un acto de representación 
en sentido técnico. Si el titular de la decisión a adoptar no puede adoptarla, la adoptan sus representantes legales, pero, en este caso, lo hacen como ejercicio de un deber velar por la persona necesitada de dicha modalidad de apoyo (Parra Lucán, 2003: 1924). Prueba de que la expresión del consentimiento informado es expresión del deber de cuidado y no propiamente sustitución de la voluntad del paciente necesitado de apoyos para prestarlo, es que la mayoría de las curatelas constituidas al amparo de la normativa anterior a la Ley 8/2021, aun respondiendo al superado binomio cuartela-asistencia, de un lado, tutela-representación del otro, han tenido por objeto la prestación del consentimiento a intervenciones y la decisión sobre tratamientos en el ámbito de la salud (curatelas de salud).

Sea como fuere, lo cierto es que el ámbito sanitario requiere una especial agilidad en la toma de decisiones y, sobre todo, la salvaguarda de la seguridad jurídica de los profesionales que han de realizar la actuación sanitaria de que se trate. Ello es lo que motiva que el sentido del término «representación» en este ámbito adquiera un sentido no técnico, sino de apoyo y sustitución en la expresión de lo que hubiera sido la voluntad del paciente de haber estado en condiciones de prestarla. Desde esta perspectiva ha de enfocarse la actuación de las personas vinculadas al paciente, a las que no es aplicable en este ámbito sanitario el nuevo art. 264 CC, según el cual, cuando excepcionalmente se requiera la actuación representativa del guardador de hecho, este habrá de obtener la autorización para realizarla a través del correspondiente expediente de jurisdicción voluntaria. En efecto, no tendría ningún sentido que la persona que de hecho ejerce el apoyo del paciente con discapacidad tuviera que acudir a este expediente judicial con el consiguiente retraso en la asistencia, y mucho menos lógico sería cargar al médico responsable del tratamiento con el deber de comprobar el cumplimiento de tal requisito. El propio inciso final del artículo, que establece que «en todo caso, quien ejerza la guarda de hecho deberá recabar autorización judicial conforme a lo indicado en el párrafo anterior para prestar consentimiento en los actos enumerados en el artículo 287». Y es precisamente este art. $287 \mathrm{CC}$ el que excluye el consentimiento informado en el ámbito de la salud del deber de recabar autorización judicial para realizar actos de transcendencia personal o familiar cuando la persona afectada no pueda hacerlo por sí misma, remitiéndose a su regulación especial.

\section{EL CONSENTIMIENTO INFORMADO EN CASO DE EXISTENCIA DE MEDIDAS DE APOYO FORMAL}

El segundo supuesto de "consentimiento por representación» contemplado en el art. 9 LAP tiene lugar "cuando el paciente tenga la capacidad modificada judicialmente y así conste en la sentencia». Bajo la vigencia de 
la redacción originaria de la Ley 41/2002, la norma se refería únicamente a "cuando el paciente esté incapacitado legalmente». El apartado ya fue objeto de acertadas críticas dirigidas a su simplicidad y a su falta de adecuación a la variedad de situaciones en las que se podía encontrar una persona sujeta a instituciones de guarda y protección en razón de su falta de capacidad: como afirma Parra Lucán (2003), podía gozar de capacidad natural suficiente para el acto, estar sometido a una curatela no representativa vigente o incapacitada únicamente para determinados actos de naturaleza patrimonial. Con posterioridad, la Ley 26/2015, de 28 de julio, de Modificación del Sistema de Protección a la Infancia y a la Adolescencia, aprovechó la necesidad de adecuar la norma a las modificaciones en el régimen jurídico del menor introducidas asimismo en la LO 1/1996, de 15 de enero, de Protección Jurídica del Menor, de modificación parcial del Código Civil y de la Ley de Enjuiciamiento Civil, para plasmar en el apdo. 9.3 la realidad de que los procesos de incapacitación se habían convertido ya en procesos de modificación judicial de la capacidad de las personas, no necesariamente constitutiva de incapacitación total. No obstante, la norma siguió sin adecuarse a la realidad de la gran variedad de situaciones posible en torno a las personas con su capacidad judicialmente modificada, tantas como los "trajes a medida" que la jurisprudencia, conforme a las exigencias del Convenio de Nueva York, recordemos, ratificado por España desde el año 2007, exigía ya confeccionar para las personas con discapacidad $^{11}$.

La entrada en vigor de la Ley 8/2021 es la ocasión propicia para adecuar la norma a una realidad añadida. En la actualidad, las medidas de provisión de apoyos de carácter judicial son subsidiarias de las de carácter voluntario previstas o acordadas por la propia persona con necesidad de ellas, así como a los apoyos de hecho si vienen resultando eficaces (art. $268 \mathrm{CC}$ ), pero lo que es más importante: la provisión de un apoyo representativo es excepcional, tanto si es puntual — cuando tras un esfuerzo considerable no se pueda determinar la voluntad de la persona requerida del mismo (art. 249 III CC) — como si es de carácter estable y formal - ya que la curatela representativa tiene carácter excepcional, concreto y motivado (art. 269 III CC)—. Es más: aun cuando exista una medida de carácter representativo (cuyo paradigma en el ámbito que nos ocupa ha pasado a constituirlo la «curatela de salud»), el criterio

11 Según esta doctrina, el juicio sobre la modificación de la capacidad no es algo rígido, sino flexible, en tanto que debe adaptarse a la concreta necesidad de protección de la persona afectada por la discapacidad, lo que se plasma en su graduación. Por todas, entre las más recientes, SSTS (1 ${ }^{\mathrm{a}}$ ) de 6 de mayo de 2021 (RJ 2021, 2381) y 18 de julio de 2018 (RJ 2018, 2957). 
determinante en la Ley 8/2021 es la posibilidad real de que la persona discapacitada determine su propia voluntad después de un esfuerzo informativo "considerable»; posibilidad a la que, por otra parte, ya apuntaba el propio art. 8 de la Ley 41/2002 en términos de "capacidad natural para comprender el alcance de la intervención».

Por lo anterior, en los casos en los que la persona a quien se ha provisto de apoyo representativo en materia de salud pueda acabar comprendiendo el alcance de la intervención y determinar su propia voluntad al respecto, el representante podrá y deberá seguir interviniendo para expresar su consentimiento en el ejercicio de los deberes de guarda y protección que le incumben en razón de su función, de forma conjunta con el consentimiento personal expresado por aquella (Santos Morón, 2000: 35). Al mismo resultado conducen el apdo. 7 del art. 9 LAP — que establece que la prestación del consentimiento por representación será «adecuada a las circunstancias y proporcionada a las necesidades que haya que atender, siempre en favor del paciente y con respeto a su dignidad personal y que el paciente participará en la medida de lo posible $\mathrm{e}^{12}$ en la toma de decisiones a lo largo del proceso sanitario»-y el art. 6.3 del propio Convenio de Oviedo, según el cual «la persona afectada podrá intervenir, en la medida de lo posible, en el procedimiento de autorización».

Ahora bien: el deber de fomentar la autonomía decisoria de la persona con discapacidad incluso después de asumir su representación es el titular del apoyo, no el profesional sanitario. A efectos de evitar incurrir en responsabilidad, al profesional le basta recabar el consentimiento del sujeto llamado a ejercer la representación del paciente, sin perjuicio de que los Estados firmantes del Convenio de Nueva York tengan el deber de «sensibilizar a sus profesionales sanitarios respecto de los derechos humanos, la dignidad, la autonomía y las necesidades de las personas con discapacidad a través de la capacitación y la promulgación de normas éticas para la atención de la salud en los ámbitos público y privado» (art. 25 de la Convención).

En definitiva, en atención a lo dispuesto en el art. 269 CC, la actual regulación del consentimiento informado requeriría un añadir un inciso

12 El artículo es trasunto de la teoría de la escala móvil de la capacidad, por la que se reconoce que la competencia del paciente varía no solo en función de sus aptitudes mentales, sino también en función de la gravedad de las consecuencias de la decisión que se adopte. Cuanto más graves, peligrosas o irreversibles son las consecuencias de la decisión para la salud del paciente, son más exigentes los criterios de capacidad exigidos (Simón Lorda, 2008: 341). En el ámbito de la minoría de edad, De Montalvo Jääskeläinen (2013: 289-305). 
al apdo. 2 del art. 4, así como una modificación de los apdos. a) y b) del art. 9.3 de la LAP, cuya redacción podría ser la siguiente:

Artículo 4:

2. En caso de que el paciente con discapacidad requiera apoyo para el ejercicio de su capacidad, el profesional responsable de su asistencia lo informará de acuerdo con sus posibilidades de comprensión, y la persona que en cada caso ejerza el apoyo necesario, realizará un esfuerzo de información considerable para que aquél pueda expresar por sí su propia voluntad, deseos y preferencias. En caso de que ello no sea posible, se estará a lo dispuesto en el art. 9.3 a).

Artículo 9:

3. Se otorgará el consentimiento por persona distinta del paciente:

a) Cuando tras un esfuerzo considerable, no sea posible en modo alguno determinar la voluntad, deseos y preferencias del paciente respecto de la actuación sanitaria, a criterio del médico responsable de la asistencia, o su estado físico o psíquico no le permita hacerse cargo de su situación. Si el paciente carece de apoyos formales, el consentimiento lo prestarán las personas que ejerzan su guarda o estén vinculadas a él por razones familiares o de hecho.

b) Cuando el paciente requiera de apoyo representativo concretado en el ejercicio de su capacidad decisoria en el ámbito de su salud y así conste en el título por el que aquél se constituya o acuerde.

La persona que preste el consentimiento en alguno de los supuestos recogidos en los dos apartados anteriores deberá atender a la voluntad, deseos y preferencias que el paciente haya manifestado de cualquier modo con anterioridad. En caso de que ello no sea posible, debe tener en cuenta la trayectoria vital de la persona con discapacidad, sus creencias y valores, así como los factores que ella hubiera tomado en consideración, con el fin de tomar por sí solo la decisión que habría adoptado la persona en caso de no requerir representación.

Sin embargo, las anteriores previsiones quedarían incompletas si no se tuvieran en cuenta las especialidades concurrentes en el ámbito de la salud, a las que se refiere el propio art. 287 CC tras su nueva redacción por la Ley 8/2021, y que obligan a añadir un párrafo más al apdo. 3 del art. 9 LAP, para recordar la posibilidad de control judicial de las decisiones adoptadas por la persona llamada a ejercer el apoyo representativo, por más que esta actúe atendiendo a la trayectoria vital de la persona con discapacidad. Veamos por qué. 


\section{BENEFICENCIA VERSUS AUTONOMÍA: EL MEJOR INTERÉS DE LA PERSONA NECESITADA DE APOYO COMO LÍMITE A LAS DECISIONES EN MATERIA DE SALUD}

El nuevo paradigma del reconocimiento de la capacidad de obrar a toda persona y el respeto a sus deseos y preferencias implica un alejamiento del esquema tradicional de la representación legal de las personas con «capacidad judicialmente modificada».

$\mathrm{El}$ art. $216 \mathrm{CC}$ anterior a la entrada en vigor de la Ley 8/2021 recordaba que todas las funciones tutelares recogidas en el cap. I del título X entonces vigente debían ser ejercidas «en beneficio» del tutelado, expresión que no se encuentra en las pautas de actuación incorporadas al nuevo título XI CC. Como segundo límite, el artículo se refería a la salvaguarda de la autoridad judicial, límite éste que sigue operando en el título XI CC actualmente vigente, si bien con algunos matices de interés.

Según la nueva redacción del art. 249 II CC, las personas que presten el apoyo a la persona con discapacidad «deberán actuar atendiendo a la voluntad, deseos y preferencias de quien lo requiera. Igualmente procurarán que la persona con discapacidad pueda desarrollar su propio proceso de toma de decisiones, informándola, ayudándola en su comprensión y razonamiento y facilitando que pueda expresar sus preferencias [...]» y solo «en casos excepcionales, cuando, pese a haberse hecho un esfuerzo considerable, no sea posible determinar la voluntad, deseos y preferencias de la persona, las medidas de apoyo podrán incluir funciones representativas». En este último caso — esto es, cuando la mera asistencia en el proceso de toma de decisiones no baste-, en el ejercicio de esas funciones se deberá tener en cuenta «la trayectoria vital de la persona con discapacidad, sus creencias y valores, así como los factores que ella hubiera tomado en consideración, con el fin de tomar la decisión que habría adoptado la persona en caso de no requerir representación». Por su parte, el art. 250 II CC insiste en que la función de las medidas de apoyo es la asistencia de la persona con discapacidad en el ejercicio de su capacidad jurídica, con respeto a la voluntad de la persona con discapacidad, a sus deseos y a sus preferencias.

La redacción de las dos normas expuestas conduce a entender que el criterio del mejor interés de la persona con necesidad de apoyos en su capacidad —el beneficio final de la actuación de la persona de apoyo-, ha sido totalmente sustituido por el respeto a la autonomía personal de la persona con discapacidad. Esto afecta en gran medida a los deberes de información asistencial y a los requisitos de la prestación del consentimiento informado actualmente regulado en la Ley 41/2002, pues el nuevo paradigma parece haber optado, al menos en general, por el principio de autonomía frente al de beneficencia. O lo que es lo mismo: a diferencia de lo que acontece en el 
caso de la representación legal de los menores por sus padres o tutores, que deben actuar siempre en beneficio del menor - lo que pasa por entender que oírlos y tener en cuenta su opinión no implica seguirla necesariamente-, toda actuación en interés de la persona con necesidad de apoyos en el ejercicio de su capacidad requerirá, precisamente, respetar su voluntad, deseos y preferencias, y llegado el caso, interpretar su trayectoria vital para deducir cuáles habrían sido estos de haber podido actuar sin representación.

La cuestión es si ello es exactamente así en el ámbito de las decisiones a adoptar en el ámbito sanitario, o si en el ámbito que nos ocupa existe algún límite que autorice, y que incluso obligue al curador representativo a actuar en beneficio de la salud y de la vida de la persona con discapacidad. En definitiva, se trata de saber si el apdo. 6 del art. 9 LAP ha de seguir vigente tras la Ley $8 / 2021$, a pesar de que establece el deber del representante de adoptar la decisión atendiendo siempre al mayor beneficio para la vida o salud del paciente en cualquiera de los supuestos descritos en los apdos. 3 a 5 , ordenando la puesta en conocimiento de la autoridad judicial de aquellas decisiones contrarias a tal interés, para que adopte la resolución correspondiente, y legitimando a los facultativos para adoptar las medidas necesarias en salvaguarda de la vida o salud del paciente en casos de urgencia, amparados por las causas de justificación de cumplimiento de un deber y de estado de necesidad.

La referencia a los apdos. 3 a 5 incluye todos los supuestos de consentimiento por representación descritos en el art. 9 LAP, así como otros contemplados en normas especiales, incluyendo también el caso de menores de edad y, en las intervenciones de grave riesgo para la salud o la vida del paciente, también de los menores de edad mayores de 16 años. Donde debe localizarse la necesidad de acudir al juez es en los efectos de la decisión del representante en relación con esos intereses considerados superiores por la norma ${ }^{13}$. Pues bien, creo que puede

13 A raíz de la crisis sanitaria por la COVID-19 han proliferado los autos dictados por los juzgados de primera instancia autorizando la vacunación obligatoria frente a la COVID-19 de ancianos, normalmente ingresados en residencias, en contra del criterio de sus representantes. Sin embargo, frente a la motivación utilizada en estas resoluciones judiciales, la Fiscalía del Tribunal Supremo emitió un dictamen el 24 de febrero de 2021 en contra de las vacunaciones forzosas contra la COVID-19 en residencias de ancianos: "En tanto que la ley no establezca obligación de vacunarse, no cabe invocar razones genéricas de salud pública o específicamente basadas en la especial vulnerabilidad de determinados grupos de personas para justificar la administración forzosa de la vacuna». Es la concreta afectación de la salud del sujeto lo que puede llevar a imponer una actuación sanitaria en contra de la decisión de sus representantes a través de lo dispuesto en el art. 9.6 LAP, y el cauce procesal adecuado es el previsto en la LJV (art. 87.1), que prevé medidas cautelares para la protección frente 
afirmarse que, con algunas adecuaciones formales, este apartado ha de seguir formando parte de la regulación legal del consentimiento informado a pesar del giro autonomista del nuevo paradigma en materia de capacidad. Las razones que sustentan esta opinión se exponen a continuación.

En primer lugar, la tensión entre autonomía y beneficencia en este ámbito es un falso dilema. Obsérvese que, a diferencia de lo previsto en el caso del menor mayor de 16 años en el art. 9.4 LAP, no se está planteando aquí la posibilidad de representar al paciente discapacitado en atención grave riesgo de la intervención. Es evidente que ello habrá tenido su importancia en la caracterización y concreción de los apoyos necesarios — ex art. $9.3 \mathrm{~b}$ ) o c) —; pero lo que ahora se discute no es si se representará o no al paciente en intervenciones de grave riesgo, como ocurre en el caso del menor de 16 años cumplidos (cuestión que sí concierne a la autonomía de este), sino la necesidad de controlar judicialmente la decisión del representante cuando la decisión sea contraria a la salud o a la vida del mismo. Por ejemplo, cuando se solicite la retirada de un soporte vital que pudiera ser discriminatoria $-\mathrm{y}$, por lo tanto, contraria al art. 25 f) de la Convención de Nueva York ${ }^{14}$ - o cuando el apoyo representativo decida rechazar o iniciar un tratamiento alternativo más arriesgado. La excepcionalidad con la que se presenta en la Ley 8/2021 la posibilidad de la actuación representativa por parte de la persona de apoyo implica que habrá fracasado todo intento de determinar la voluntad, deseos y preferencias de la persona representada, siquiera a través de un documento de instrucciones previas o voluntades anticipadas (art. $11 \mathrm{LPA}$ ), el cual, por definición, elimina la posibilidad de consentimiento por representación ${ }^{15}$. Asimismo, en el caso de que la propia persona con discapacidad haya dispuesto una provisión de medidas de carácter representativo en previsión de la futura necesidad de apoyos en el ejercicio de su capacidad, el principio de autonomía tampoco queda comprometido, pues la propia persona habrá dispuesto el ámbito de su propia representación. En definitiva, en caso de imposibilidad de determinación de la voluntad, deseos

al ejercicio inadecuado de la potestad de guarda de personas con apoyos a su capacidad modificada judicialmente.

14 Según dicho artículo, los Estados firmantes, «f) Impedirán que se nieguen, de manera discriminatoria, servicios de salud o de atención de la salud o alimentos sólidos o líquidos por motivos de discapacidad».

15 El art. 11.1 LAP prevé la posibilidad de que el otorgante del documento puede designar, además, un «representante» para que, llegado el caso, sirva como interlocutor suyo con el médico o el equipo sanitario para procurar el cumplimiento de las instrucciones previas. No se trata de un verdadero supuesto de representación, sino de interlocución o garantía de cumplimiento de una voluntad ya emitida (González Morán, 2008). En la actualidad, podríamos hablar de apoyo no representativo de carácter voluntario previsto de forma anticipada. 
y preferencias de la persona con discapacidad, la norma ordena al representante actuar conforme a la trayectoria vital del representado, sus creencias y valores, así como los factores que ella hubiera tomado en consideración a la hora de adoptar la decisión; pero se trata de una decisión heterointegrada que ya habrá dejado atrás el principio de autonomía y que, por lo tanto, no puede primar sobre el deber de los poderes públicos de salvaguardar la vida y la integridad física de la persona con discapacidad (arts. 17 y 25 de la Convención de Nueva York y art. 10 del TR RDLeg 1/2013).

En segundo lugar, la propia modificación del art. 287 CC por la Ley 8/2021 da cuenta de las especialidades del ámbito sanitario cuando, tras enumerar los actos para los que el titular de la función representativa requiere autorización judicial, se remite a lo dispuesto en la legislación específica en materia de consentimiento informado y de internamiento no voluntario de la persona con discapacidad. Parece lógico entender que, en materia de autorización judicial de la actuación del curador representativo en materia de salud, la Ley 8/2021 ha querido dejar subsistentes las cautelas previstas en el apdo. 6 del art. 9 LPA. Es más: llegado el caso, la decisión judicial se decantará por la preservación de la salud de la persona con discapacidad intelectual sin más indagación en sus preferencias; pues, como afirma la la STS (1 $\left.1^{a}\right)$ de 8 de septiembre de 2021 (RJ 2021\4002), a pesar de las buenas intenciones de la Ley $8 / 2021$, sería una "crueldad social» no intervenir sustituyendo la voluntad en contra manifestada por la persona afectada por un trastorno mental (en el caso, síndrome de Diógenes), que es, precisamente, el que no le permite ser consciente del proceso de degradación personal que sufre.

Hasta aquí se ha expuesto una propuesta para el régimen general del consentimiento informado en el ámbito de la salud que se ha considerado coherente con el nuevo paradigma de apoyos a la capacidad introducido por la Ley 8/2021. Sin embargo, el art. 9.5 de la LAP establece reglas especiales para la práctica de ensayos clínicos, para la interrupción voluntaria del embarazo y para la práctica de técnicas de reproducción asistida; y otras normas regulan actuaciones sanitarias que son objeto de regulación específica en cuanto a la prestación del consentimiento (trasplantes, eutanasia).

\section{LOS APOYOS A LA PRESTACIÓN DEL CONSENTIMIENTO INFORMADO EN CASOS ESPECIALES}

\section{ENSAYOS CLÍNICOS}

El art. 6 del RD 1090/2015, de 4 de diciembre, por el que se regulan los ensayos clínicos con medicamentos, los Comités de Ética de la Investigación 
con medicamentos y el Registro Español de Estudios Clínicos, se dirige a regular los «ensayos clínicos con personas con la capacidad modificada para dar su consentimiento» con una confusa redacción que viene a complicarse más si cabe por la vigencia (y las remisiones expresas en su texto) del Reglamento (UE) 536/2014, de 16 de abril, sobre ensayos clínicos de medicamentos de uso humano, directamente aplicable en todos los países miembros. Las exigencias de dicho artículo pueden resumirse como sigue:

a) Cuando se trate de un individuo adulto sin «capacidad suficiente» para otorgar su consentimiento informado, debe prestarlo el representante legal de este una vez informado, si bien el consentimiento debe reflejar la voluntad del sujeto y puede ser retirado en cualquier momento sin perjuicio para este.

b) Siempre que las condiciones del sujeto lo permitan, este debe prestar además su consentimiento para participar en el ensayo, después de haber recibido toda la información pertinente adaptada a sus posibilidades de comprensión, incluida la posibilidad de retirarse del ensayo.

c) El investigador puede obtener el consentimiento de la persona vinculada al paciente por razones familiares o de hecho cuando se trate de un ensayo de urgencia no requerido de consentimiento según el art. 7 del $\mathrm{RD}$ (ensayos urgentes en casos de necesidad, con un interés específico para la población sobre la que se realiza la investigación, conformes al art. 35, apdos. 1 y 2, del Reglamento (UE) 536/2014).

d) En todo caso, el investigador principal del ensayo debe asegurarse razonablemente de que no existen instrucciones previas de la persona expresadas al respecto con anterioridad a la modificación de su capacidad, en cuyo caso habrán de ser respetadas.

Las diferencias con los requisitos del consentimiento informado de personas con necesidad de apoyo en el ejercicio de su capacidad regulado en la LAP son dos:

- En primer lugar, la persona con discapacidad codecide con su «representante legal» (léase "titular del apoyo») otorgando su consentimiento junto con el de este. Se trata de un régimen más respetuoso con la dignidad y el derecho a la integridad física que el general previsto en la LAP, en el que, como se ha propuesto en páginas anteriores, debería introducirse la necesidad de contar también con el consentimiento de la persona requerida de apoyo en función de su grado de autodeterminación, fomentando esta a través de una información adecuada a sus posibilidades de comprensión.

- En segundo lugar, la norma exige al investigador asegurarse de que no existen instrucciones previas de la persona expresadas al respecto antes de 
presentar una modificación de su capacidad, lo cual es una mejora que se debería introducir en el régimen general del art. 9 de la LAP.

\section{INTERRUPCIÓN VOLUNTARIA DEL EMBARAZO}

El Convenio de Nueva York, en su art. 23 b), exige a los Estados firmantes que se respete el derecho de las personas con discapacidad a decidir libremente y de manera responsable el número de hijos que quieren tener y el tiempo que debe transcurrir entre un nacimiento y otro, y a tener acceso a la información, educación sobre reproducción y planificación familiar apropiadas para su edad, y que les ofrezcan los medios necesarios que les permitan ejercer esos derechos. Por su parte, el art. 25 a) ordena a los Estados firmantes proporcionar a las personas con discapacidad programas de atención en el ámbito de la salud sexual y reproductiva en condiciones de igualdad.

Tras una evolución atormentada ${ }^{16}$, el art. 9.5 II de la LAP actualmente vigente establece que para la interrupción voluntaria del embarazo de menores de edad o "personas con capacidad modificada judicialmente» es preciso, además de su manifestación de voluntad, el consentimiento expreso de sus representantes legales. El inciso final del apartado acaba ordenando que, "en este caso», los conflictos que surjan en cuanto a la prestación del consentimiento por parte de dichos representantes se resolverán de conformidad con lo dispuesto en el Código Civil. Además, se elimina acertadamente la referencia a la posibilidad de actuar sin dicho consentimiento en casos de riesgo vital, puesto que dicha excepción está contemplada de forma general en el art. 9.2 b) para el caso de que exista riesgo inmediato grave para la integridad física o psíquica del enfermo y no sea posible conseguir su autorización.

La principal diferencia de este régimen con el general del consentimiento informado regulado en el apdo. 3 del art. 9 es la necesidad de que el

16 La redacción originaria del art. 9 LAP, en su apdo. 4, se remitía a las disposiciones sobre la mayoría de edad y a la legislación especial aplicable, sin hacer referencia a las situaciones de incapacidad. La LO 2/2010 reguló los requisitos de edad y capacidad para interrupción voluntaria del embarazo - exigiendo el consentimiento expreso y por escrito de la mujer embarazada o, en su caso, del representante legal conforme a la LAP, pudiendo prescindir de dicho consentimiento expreso en el supuesto previsto en el artículo 9.2.b) de la referida Ley (cuando existe riesgo inmediato grave para la integridad física o psíquica del enfermo y no es posible conseguir su autorización, consultando, cuando las circunstancias lo permitan, a sus familiares o a las personas vinculadas de hecho a él)-. La LO 8/2015, de modificación del sistema de protección de la infancia y la adolescencia, modificó este artículo introduciendo el apdo. 9.5 II actualmente vigente. 
paciente representado legalmente participe en el proceso consintiendo con una declaración expresa de voluntad, con independencia de sus posibilidades de entender el alcance de la intervención. De ahí la previsión de que «en este caso» los conflictos entre el representante legal y la mujer gestante se resuelvan conforme a lo dispuesto en el Código Civil, lo que sin duda quiere subrayar que, en este caso, el facultativo responsable no puede prescindir de su consentimiento y que la cuestión se judicializará necesariamente a través del trámite procesal indicado en el art. 87.1 LJV, aunque, según su criterio, aquella no sea capaz de comprender el alcance de la intervención, siempre sin perjuicio de lo dispuesto en el art. 9.2 b) de la LAP.

Se trata de una solución garantista de la libertad procreativa de la mujer con discapacidad intelectual, si bien, llegado el caso, le será aplicable de forma prioritaria ya en sede judicial (o en caso de urgencia, en sede sanitaria, amparado el profesional por la existencia de un deber de actuación en estado de necesidad) el criterio del beneficio para su salud o su vida (art. 9.6 de la LAP). Por lo tanto, entiendo que la modificación de este apartado, bien podría limitarse a expresar:

Para la interrupción voluntaria del embarazo de menores de edad o personas con necesidad de apoyos en su capacidad será preciso, además de su manifestación expresa de voluntad, el consentimiento expreso del representante legal de la menor o de la persona nombrada para ejercer la representación de la mujer en el ámbito de las decisiones sobre su salud. En el caso de que la mujer carezca de un apoyo representativo y, según el criterio del médico responsable no pueda entender el alcance de la intervención solicitada, promoverá la provisión de un apoyo representativo de acuerdo con lo previsto en el art. 87 de la LJV. Los posibles conflictos entre la gestante y sus representantes o apoyos se resolverán por el trámite procesal previsto en dicha norma.

\section{TRASPLANTES}

Los requisitos del consentimiento necesario para la donación de órganos entre personas vivas están recogidos en el art. 4 de la Ley de Extracción y Trasplante de Órganos de 6 de noviembre de 1979, desarrollada por el art. $8 \mathrm{RD}$ 1723/2012, de 28 de diciembre, por el que se regulan las actividades de obtención, utilización clínica y coordinación territorial de los órganos humanos destinados al trasplante y se establecen requisitos de calidad y seguridad. Dicha norma, junto con el expediente de jurisdicción voluntaria regulado en los arts. 78 a $80 \mathrm{LJV}$, constituyen el marco legal de la autonomía decisoria en materia de trasplantes de órganos. 
El art. 4 de la ley exige que el donante sea mayor de edad, que esté en pleno uso de sus facultades mentales, y que haya sido previamente informado de las consecuencias de su decisión. La norma insiste en su párrafo último en que no podrá obtenerse ningún tipo de órganos de personas que, por deficiencias psíquicas o enfermedad mental o por cualquier otra causa, no puedan otorgar su consentimiento expreso, libre y consciente. Por su parte, el art. 8 del RD $1723 / 2012$ añade el requisito de «desinteresado» al consentimiento y establece, en su letra d), que «el donante no deberá padecer o presentar deficiencias psíquicas, enfermedad mental o cualquier otra condición por la que no pueda otorgar su consentimiento en la forma indicada. Tampoco podrá realizarse la obtención de órganos de menores de edad, aun con el consentimiento de los padres o tutores».

El último inciso de este apartado aparta la donación de órganos de los actos que se pueden llevar a cabo por representación, de acuerdo con lo dispuesto para este ámbito en el art. 20 del Convenio de Oviedo. Por lo tanto, ni el curador ni ningún otro guardador puede otorgar el consentimiento en sustitución del sujeto necesitado de apoyos. La cuestión es si la referencia al "pleno uso» de las facultades mentales elimina también la posibilidad de que el potencial donante con necesidad de apoyos no representativos en el ejercicio de su capacidad pueda prestar consentimiento válido a este efecto. Creo que ello no es necesariamente así, y que la normativa sobre trasplantes parte de la constatación médica y el control judicial de la aptitud natural del sujeto para otorgar el consentimiento — con o sin apoyos, pero excluyendo cualquier tipo de representación-.

Así, el art. $156 \mathrm{CP}$, al regular los casos en los que la extracción de órganos para el trasplante está exenta de responsabilidad penal, establece que «el consentimiento válida, libre, consciente y expresamente emitido exime de responsabilidad penal [...] salvo que el consentimiento se haya obtenido viciadamente (sic), o mediante precio o recompensa, o el otorgante sea menor de edad o carezca absolutamente de aptitud para prestarlo, en cuyo caso no será válido el prestado por éstos ni por sus representantes legales».

La norma corrobora que la necesidad de apoyo representativo y la aptitud para prestar consentimiento válido para actuar como donante no son compatibles; pero que sí puede serlo el prestado por la persona requerida de apoyo en el ejercicio de su capacidad —en la práctica, sometida a curatela no representativa en este ámbito-, si supera el control establecido en el expediente regulado en los arts. 78 a $80 \mathrm{LJV}$, que exige que a la solicitud de donación se acompañe el certificado médico sobre la salud mental y física del donante y otras garantías de respeto a la voluntad del donante, como el interrogatorio judicial personal, y la audiencia a los profesionales intervinientes en el proceso. En definitiva, el consentimiento puede ser expreso, libre 
y consciente precisamente gracias al apoyo, pues ese y no otro es el objetivo de esta medida según el art. 249 CC (procurar que la persona con discapacidad "pueda desarrollar su propio proceso de toma de decisiones, informándola, ayudándola en su comprensión y razonamiento y facilitando que pueda expresar sus preferencias»).

A lo anterior ha de unirse una última reflexión en favor de la posibilidad de que el sujeto con necesidad de apoyos no representativos pueda ser donante de órganos: en la actualidad, existen modalidades de trasplantes que sí llevan consigo un beneficio para el donante, como ocurre con la donación cruzada o en cadena.

En cuanto al receptor, el art. 6 de la Ley de Trasplantes ya está redactado de forma acorde con la Ley de Apoyos. En él se establece que «en el caso de que sea una persona con discapacidad, deberán tenerse en cuenta las circunstancias personales del individuo, su capacidad para tomar dicha decisión en concreto y contemplarse la prestación de apoyo para la toma de estas decisiones. Tratándose de personas con discapacidad con necesidades de apoyo para la toma de decisiones, se estará a la libre determinación de la persona una vez haya dispuesto de los apoyos y asistencias adecuados a sus concretas circunstancias»; pero, en caso contrario, cuando tras un esfuerzo considerable, no sea posible que el receptor determine su voluntad, ¿procederá el nombramiento de un apoyo de carácter representativo, y el consentimiento se otorgará por este junto con la voluntad del donante en la medida en que pueda otorgarla, y siempre en beneficio de su salud, en virtud de lo dispuesto en el art. 9.3 de la LAP? ¿podrá judicializarse el otorgamiento del consentimiento en el caso de que el trasplante sea la única forma de preservar la salud del paciente con discapacidad? Creo que así debe considerarse, y que la posibilidad prevista por el art. 9.6 de la LAP, introducida con posterioridad por la Ley 26/2015, es también aplicable a este supuesto.

En lo que respecta a la donación de células y tejidos humanos para su donación e implantación en terceras personas, el art. 7 del RD Ley 9/2014, de 4 de julio ${ }^{17}$ impide igualmente la obtención de células y tejidos de personas menores de edad o de personas que por deficiencias psíquicas, enfermedad mental, incapacitación legal (sic) o cualquier otra causa, no puedan otorgar su consentimiento, descartando igualmente la posibilidad de representación legal. Sin embargo, se exceptúa el caso de que «se trate de residuos quirúrgicos

17 «Por el que se establecen las normas de calidad y seguridad para la donación, la obtención, la evaluación, el procesamiento, la preservación, el almacenamiento y la distribución de células y tejidos humanos y se aprueba las normas de coordinación y funcionamiento para su uso en humanos.» 
o de progenitores hematopoyéticos u otros tejidos o grupos celulares reproducibles cuya indicación terapéutica sea o pueda ser vital para el receptor». En estos casos, el consentimiento será otorgado por quien ostente la representación legal. También se permite otorgar el consentimiento por representación en los casos de uso autólogo o autólogo eventual.

Una adecuación de esta normativa al nuevo paradigma de apoyos a la capacidad obligaría a añadir:

[...] la donación, incluso la alogénica o a tercera personas, será posible con apoyos, siempre y cuando el consentimiento lo exprese la persona requerida de ellos para la elaboración de su decisión; y que en los casos en que el consentimiento pueda y deba otorgarlo el curador o guardador con función es de representación, la persona otorgará su consentimiento juntamente con éste en la medida de sus posibilidades de comprensión.

\section{REPRODUCCIÓN ASISTIDA}

La Ley 14/2006, de 26 de mayo, reguladora de las Técnicas de Reproducción Humana Asistida, exige "plena capacidad» en la persona receptora de las técnicas. Por lo tanto, se excluye la validez del consentimiento por representación, pero en este caso, entendemos que también la validez del prestado por la mujer provista de medidas de apoyo no representativo o de mera asistencia para el ejercicio de su capacidad que incluyan la toma de decisiones en el ámbito sanitario. A esta conclusión conduce, no tanto la exigencia de "plena» capacidad, sino la inexistencia de controles judiciales, médicos e institucionales que vengan a verificar, como es preceptivo en el caso de los trasplantes, la aptitud de la mujer para prestar un consentimiento acorde con la importancia y los riesgos del tratamiento, así como para asimilar las implicaciones jurídicas que forman parte de la información necesaria a los efectos de otorgar un verdadero consentimiento informado.

No obstante, la anterior solución debe ser matizada con lo que en cada caso disponga la resolución o el acuerdo por el que se establezca la medida de apoyo. Porque lo hasta ahora dicho parte del uso de las técnicas de reproducción asistida como mecanismo capaz de articular la libertad de procreación, pero la realidad es más compleja. Las técnicas tienen como objetivo no único, pero sí principal, remediar la infertilidad, y el art. $1.1^{\circ}$ LTRHA prevé también la aplicación de las técnicas de reproducción asistida «en la prevención y tratamiento de enfermedades de origen genético» - lo que hace referencia a la técnica del diagnóstico genético preimplantacional para la detección de enfermedades hereditarias graves no susceptibles de tratamiento curativo 
postnatal (art. 12 LTRHA, sujeto a comunicación posterior a la autoridad sanitaria competente); y también se prevé su uso con fines terapéuticos para terceros (que exige autorización expresa de dicha autoridad, previo informe de la Comisión Nacional de Reproducción Humana Asistida)- En los tres casos se podría pensar que se trata de decisiones que afectan al derecho proclamado en el art. 23.1, b), y c) del Convenio de Nueva York, que ordena a los Estados firmantes que «se respete el derecho de las personas con discapacidad a decidir libremente y de manera responsable el número de hijos que quieren tener y el tiempo que debe transcurrir entre un nacimiento y otro, y a tener acceso a la información, educación sobre reproducción y planificación familiar apropiados para su edad, y se ofrezcan los medios necesarios que les permitan ejercer esos derechos, y que las personas con discapacidad, incluidos los niños y las niñas, mantengan su fertilidad, en igualdad de condiciones con las demás». Entiendo, sin embargo, que dichos derechos se enuncian en el Convenio a modo de interdicción de normas dirigidas a la planificación familiar forzosa y a la esterilización, de la que es ejemplo la LO 2/2020, de 16 de diciembre, de modificación del Código Penal para la erradicación de la esterilización forzada o no consentida de personas con discapacidad incapacitadas judicialmente ${ }^{18}$.

\section{EUTANASIA}

Puede parecer contradictorio con los principios de la Convención de Nueva York ligar el tratamiento de la LO 3/2021, reguladora de la eutanasia, con los derechos de las personas con discapacidad. Pero la asociación de ideas resulta de obligado análisis, toda vez que el legislador, pese a la postura contraria del Comité Español de Representantes de Personas con discapacidad (CERMI) ${ }^{19}$ y del Comité sobre los Derechos de las Personas

18 Precisamente, la disp. final tercera de dicha norma ordena al Gobierno la remisión a las Cortes Generales un proyecto de ley de modificación de la Ley 41/2002, de 14 de noviembre, básica reguladora de la autonomía del paciente y de derechos y obligaciones en materia de información y documentación clínica, y de la Ley Orgánica $2 / 2010$, de 3 de marzo, de salud sexual y reproductiva y de la interrupción voluntaria del embarazo. No parece, sin embargo, que la norma esté pensando en el acceso de las personas con discapacidad intelectual a los medios de reproducción asistida, sino a la accesibilidad a la información necesaria para los actos en los que su consentimiento es necesario (v. gr. métodos de planificación familiar e interrupción voluntaria del embarazo).

19 El CERMI se dirigió al Defensor del Pueblo solicitando la interposición de un recurso de inconstitucionalidad contra la Ley Orgánica 3/2021, de 24 de marzo, por incurrir 
con Discapacidad de Naciones Unidas ${ }^{20}$, ha incluido en el contexto eutanásico el «padecimiento grave, crónico e imposibilitante» y lo ha definido (art. 3 b) como:

situación que hace referencia a limitaciones que inciden directamente sobre la autonomía física y actividades de la vida diaria, de manera que no permite valerse por sí mismo, así como sobre la capacidad de expresión y relación, y que llevan asociado un sufrimiento físico o psíquico constante e intolerable para quien lo padece, existiendo seguridad o gran probabilidad de que tales limitaciones vayan a persistir en el tiempo sin posibilidad de curación o mejoría apreciable que en ocasiones puede suponer la dependencia absoluta de apoyo tecnológico.

El art. 5 de la LO 3/2021 establece que para poder recibir la prestación de ayuda para morir será necesario ser mayor de edad (entendiendo por tal la mayoría de edad general), y ser "capaz y consciente» en el momento de la solicitud [art. 5.1a) $]^{21}$. Pero no será necesario formular las dos solicitudes previas, ni haber prestado el consentimiento ad hoc en aquellos casos en los que el médico responsable certifique que el paciente situado en el contexto eutanásico descrito en el apdo. d) del art. 5 no se encuentra en el pleno uso de sus facultades ni puede prestar su conformidad libre, voluntaria y consciente para realizar las solicitudes, siempre y cuando haya suscrito con anterioridad un documento de instrucciones previas, testamento vital, voluntades anticipadas o documentos equivalentes legalmente reconocidos, en cuyo caso se podrá facilitar la prestación de ayuda para morir conforme a lo dispuesto en dicho documento. En el caso de haber nombrado «representante» en

presuntamente en discriminación por razón de discapacidad en lo que respecta a la definición del con texto eutanásico. La petición fue rechazada por existir otros recursos interpuestos contra la misma norma (fuente: Cermi.es semanal num. 443. https://bit.ly/3FjXVH4

20 «Opinión del Comité sobre los Derechos de las Personas con Discapacidad sobre el proyecto de ley de eutanasia, publicado en el $B O E$ el 10 de diciembre de 2020. En respuesta a solicitud del CERMI bajo el artículo 37.2 de la Convención y Reglas de Procedimiento del Comité». Disponible en: https://bit.ly/3b1wNje.

21 Como quiera que el art. 11 de la Ley 41/2002 establece la mayoría legal para otorgar voluntades anticipadas en materia de salud, sin que quepa representación en este ámbito personalísimo, el menor de edad no puede ser en ningún caso acreedor de la prestación de ayuda para morir, ni siquiera aquellas CC. AA. en las que la normativa sanitaria les permite otorgarlas (Andalucía, Valencia, Navarra y Aragón). La edad de 18 años es requisito ineludible a fin de que quienes realizan la prestación sanitaria eviten el tipo de penal de homicidio o auxilio al suicidio, según la modalidad eutanásica elegida por el paciente. 
ese documento, este será el interlocutor válido para el médico responsable, conforme a lo que dispone el art. 11 de la Ley 41/2002.

El requisito de capacidad y consciencia en el paciente y la posibilidad de anticipar el consentimiento eutanásico en un documento de instrucciones previas, cuya realización ordena promover la disp. adic. $7^{\text {a }}$ de la LO 3/2021 en este ámbito, plantea dos problemas de interés.

En primer lugar, si el paciente es capaz para solicitar la prestación de ayuda a morir, la existencia de un documento de instrucciones previas no exime de completar el proceso de información, solicitud y consentimiento previsto en la norma. El art. 5.2 LO 3/2021 deja claro que queda descartada la formación de la voluntad por medio de apoyos representativos, incluyendo el representante nombrado en instrucciones previas, a pesar de que algunas normas autonómicas ${ }^{22}$ consideren posible que el mismo vaya más allá de la mera interlocución con el equipo responsable, para sustituir al paciente en su decisión. Según su ordinal 2, «la decisión de solicitar la prestación de ayuda para morir ha de ser una decisión autónoma, entendiéndose por tal aquella que está fundamentada en el conocimiento sobre su proceso médico, después de haber sido informada adecuadamente por el equipo sanitario responsable», y que «se garantizarán los medios y recursos de apoyo, materiales y humanos que resulten precisos para que su decisión sea individual, madura y genuina, $\sin$ intromisiones, injerencias o influencias indebidas».

Sin embargo, en un contexto jurídico en el que la capacidad se predica de todo sujeto a pesar de la necesidad de apoyos, ¿será el médico responsable quien decida sobre la posibilidad del paciente de determinar su voluntad o será necesaria la autorización judicial en el mismo momento en que se detecte la existencia de apoyos, bien formales o bien de hecho, o incluso su necesidad? Se da la paradoja de que la autorización judicial — tanto la prevista en el art. 287 CC como la que se exige en el art. 9.6 LAP para el caso de que la decisión del representante sea contraria a la salud o a la vida del paciente- solo se exige en el caso de que el apoyo sea representativo; y si, por otra parte, partimos de la capacidad de autodeterminación decisoria que debe poseer toda persona provista de apoyos no representativos, estaríamos entendiendo que la solicitud de eutanasia se podría solicitar a través de la voluntad del paciente conformada con apoyos, bien de hecho, bien formalmente constituidos.

22 Véanse el art. 8.1 de la Ley catalana 21/2000, de 29 de diciembre, sobre los derechos de información concernientes a la salud y la autonomía del paciente, y la documentación clínica; y en Aragón, los arts. 15 de la Ley 6/2002, de 15 de abril, de Salud de Aragón, y 9.3 de la Ley 10/2011, de 24 de marzo, de derechos y garantías de la dignidad de la persona en el proceso de morir y de la muerte. 
La cuestión de si la formación de la voluntad con necesidad de apoyos no representativos es «individual, madura y genuina» en el sentido del art. 4.2 de la LO 3/2021, y en caso afirmativo, como se puede garantizar que ello se lleve a cabo «sin intromisiones, injerencias o influencias indebidas» conforme a la misma norma, no ha sido resuelta por la LO 3/2021, a pesar de que su tramitación fue paralela a la de la Ley 8/2021. Pero creo que la norma está excluyendo la posibilidad de que las personas necesitadas de apoyo para la determinación de su voluntad en el ejercicio de su capacidad puedan solicitar la prestación de ayuda a morir. Por lo tanto, el art. 4 in fine LO 3/2021, según el cual «se adoptarán las medidas pertinentes para proporcionar acceso a las personas con discapacidad al apoyo que pueden necesitar en el ejercicio de los derechos que tienen reconocidos en el ordenamiento jurídico", establece la necesidad de apoyo a la discapacidad física o sensorial en el acceso al proceso, pero no permite entender como plenamente capaz al sujeto requerido de apoyos para la determinación de su voluntad. En definitiva, la norma ha optado por el protagonismo de la percepción del médico y ha confiado en el control de la respectiva Comisión autonómica de Garantía y Evaluación de la prestación de ayuda a morir a la hora de determinar la capacidad necesaria para solicitar y consentir la eutanasia. A esta conclusión conduce asimismo la definición de «incapacidad de hecho» contenida en la LO 3/2021, como «aquella situación en la que el paciente carece de entendimiento y voluntad suficientes para regirse de forma autónoma, plena y efectiva por sí mismo, con independencia de que existan o se hayan adoptado medidas de apoyo para el ejercicio de su capacidad jurídica» y la existencia de un protocolo ministerial ${ }^{23}$ sobre «incapacidad de hecho» (sic) que, de arrojar un resultado contrario a la «plena capacidad» (sic) del solicitante, abre una única puerta: la de la verificación de la existencia de mandato eutanásico en las instrucciones otorgadas por este con anterioridad (art. 9).

En el caso de que a través de las tres fases en las que se articula el protocolo se concluyera que el paciente no es "plenamente capaz» según la norma para solicitar y consentir la eutanasia, surgen otros problemas. Una de las objeciones comúnmente dirigidas al recurso al documento de instrucciones previas es que la situación prevista por el sujeto en el mismo puede no coincidir exactamente con la que se produce en la realidad. Esto es: siempre permanece la duda de si la imposibilidad de revocación expresa se ha debido, precisamente, a la incapacidad posterior del paciente (Domínguez Luelmo, 2021). Pero además de esta tradicional objeción, la estructura del control establecido por la norma plantea un déficit de control previo por parte de la Comisión de Garantía

23 El protocolo está disponible en: https://bit.ly/3b0FkDa. 
y Evaluación (González Carrasco, 2021). Y ello porque, a diferencia de la necesidad de control previo que establece el art. 10 en el caso del paciente autónomo, en el caso del paciente no capacitado para solicitar la prestación de ayuda para morir, únicamente se exige el control ex post previsto en el art. 12, ya que el art. 9 se limita a decir que «en los casos previstos en el art. 5.2, el médico responsable está obligado a aplicar lo previsto en las instrucciones previas o documento equivalente».

\section{BREVE RESUMEN DE PROPUESTAS}

El nuevo paradigma de apoyos a la capacidad derivado de la Convención de Nueva York e incorporado a nuestra legislación civil por la Ley 8/2021 implica un esfuerzo de adecuación de la normativa vigente en materia de autonomía del paciente, tanto en sus aspectos formales como materiales. Sin embargo, el ámbito de la salud presenta algunas especialidades que matizan la primacía de la voluntad, deseos y preferencias expresados por la persona necesitada de apoyos. La tensión entre el principio de autonomía impulsado por la Ley 8/2021 y el principio de beneficencia anteriormente consagrado en el $216 \mathrm{CC}$, ha de resolverse en favor del primero, pero con el límite subsistente del art. 9.6 LAP (grave riesgo para la salud o la vida de la persona con discapacidad), que, por lo tanto, debe ser mantenido en dicha norma en el caso de una futura modificación.

Además, el ámbito sanitario requiere una especial agilidad en la toma de decisiones y la salvaguarda de la seguridad jurídica de los profesionales que han de realizar la actuación sanitaria de que se trate. Desde esta perspectiva ha de enfocarse la actuación de las personas vinculadas de hecho al paciente, a las que no es aplicable en este ámbito sanitario la autorización judicial para las actuaciones representativas que exige la nueva redacción del art. 264 CC.

Generalizando la regla establecida en la legislación especial dirigida a determinadas intervenciones en el ámbito de la salud, la futura modificación de la LAP debería incorporar la necesidad de contar con el consentimiento de la persona requerida de apoyo junto con el de su representante, en función de su grado de autodeterminación, fomentando esta a través de una información adecuada a sus posibilidades de comprensión.

Las propuestas realizadas a lo largo de este estudio podrían ser incorporadas con ocasión de la modificación normativa anunciada por la disposición final tercera de la LO 2/2020, de 16 de diciembre, de modificación del Código Penal. 


\section{Bibliografía}

Cadenas Osuna, D. (2018). El consentimiento informado y la responsabilidad médica. Madrid: Boletín Oficial del Estado.

Comité Español de Representantes de Personas con Discapacidad. Cermi.es semanal (443). Disponible en: https://bit.ly/30M1Dum.

De Montalvo Jääskeläinen, F. (2013). El menor: un paciente complicado, al menos desde el punto de vista legal. Revista CESCO de Derecho de Consumo, 8, 289305. Disponible en: https://bit.ly/3lYjlD1.

De Salas Murillo, S. (2013). Repensar la curatela. Derecho Privado y Constitución, 27, 11-48.

Domínguez Luelmo, A. (2021). Voluntades anticipadas y prestación de ayuda para morir. En C. Tomás-Valiente Lanuza (ed.). La eutanasia a debate: primeras reflexiones sobre la Ley Orgánica de Regulación de la Eutanasia (pp. 119-153). Madrid: Marcial Pons.

Fiscalía General del Estado. Instrucción 3/2010. Sobre la necesaria fundamentación individualizada de las medidas de protección o apoyo en los procedimientos sobre determinación de la capacidad de las personas. Disponible en: https://bit.ly/3DYuKZG.

Galán Cortés, J. C. (2001). Responsabilidad médica y consentimiento informado. Madrid: Civitas.

González Carrasco, M. C. (2021). LO 3/2021, reguladora de la eutanasia: seis cuestiones acerca de la prestación de la ayuda para morir. Publicaciones Jurídicas. [blog], 23-4-2021. Disponible en: https://bit.ly/3C5C8Sx.

González Morán, L. (2008). La figura y función del «representante» en la legislación sobre instrucciones previas (ley 41/2002 y legislación autonómica). En S. Adroher Biosca, F. de Montalvo Jääskeläinen, Ma . R. Corripio Gil-Delgado y A. B. Veiga Copo (coords.). Los avances del derecho ante los avances de la medicina (pp. 635-652). Pamplona: Aranzadi Thomson Reuters.

ONU. Comité para los derechos de las personas con discapacidad (2019). Informe 2019 del Comité de la ONU sobre los derechos de las personas con discapacidad. Disponible en: https://bit.ly/3joJ7OZ.

- (2020). Opinión del Comité sobre los Derechos de las Personas con Discapacidad sobre el proyecto de ley de Eutanasia, publicado en el BOE el 10 de diciembre de 2020. En respuesta a solicitud del Comité sobre los Derechos de las Personas con Discapacidad bajo el artículo 37.2 de la Convención y Reglas de Procedimiento del Comité. Disponible en: https://bit.ly/3aZBPfY.

Parra Lucán, M. A. (2003). La capacidad del paciente para prestar válido consentimiento informado. El confuso panorama legislativo español. Aranzadi Civil, 1, 1901-1930.

Santos Morón, M. J. (2000). Incapacitados y derechos de la personalidad: tratamientos médicos, honor, intimidad e imagen. Madrid: Escuela Libre Editorial.

Simón Lorda, P. (2008). La capacidad de los pacientes para tomar decisiones: una tarea todavía pendiente. Revista de la Asociación Española de Neuropsiquiatría, 28(2), 327-350. 